\title{
Influences of Aquiculture on Ecological Environment
}

\author{
Guangjun Wang \\ Pearl River Fisheries Research Institute, Chinese Academy of Fishery Sciences \\ Guangzhou 510380, China \\ Tel: 86-20-8161-6178Ｅ-mail: gjwang@prfri.ac.cn \\ Jun Xie \\ Pearl River Fisheries Research Institute, Chinese Academy of Fishery Sciences \\ Guangzhou 510380, China \\ Guangping Yin \\ South China Agricultural University \\ Guangzhou 510642, China \\ Deguang Yu, Ermeng Yu, Haiying Wang \& Wangbao Gong \\ Pearl River Fisheries Research Institute, Chinese Academy of Fishery Sciences \\ Guangzhou 510380, China
}

The research is financed by the Chinese National Project of Advanced and New Technology (863) (No. 2007AA10Z239), the Earmarked fund for Modern Agro-industry Technology Research System (No. nycytx-49), the Science and Technology Plan Project of Guangdong Province(No. 2009B020315008), the Open Fund of Key Laboratory of Genetic Breeding and Aquaculture Biology of Freshwater Fishes, Ministry of Agriculture (No. BM2007-03), the National Key Technologies $R$ \& D Program of China (No. 2006BAD03B0102), and the National Science Foundation of Guangdong Province (No. 5004159). (Sponsoring information)

\begin{abstract}
Since reforming and opening to the outside world, Chinese aquiculture has developed very quickly. The total output of aquiculture has been ranking first in the world over ten years, but it still has many problems. In the article, these problems which existing in the aquiculture of China are listed, and they have seriously influenced the quality of aquatic products of China and destroyed the whole ecological environment of aquiculture. The factors influencing the water environment include: (1) residual feeds and excrements, (2) chemical medicines used in aquiculture, (3) escaping aquatic animals. And the aspects which were influenced including: (1) the influence on the physiochemical factor of water, (2) the influence on the bottom matters, (3) the influence on the plankton, and (4) the influence on the bottom dwellers are analyzed. To reduce the influence and pollution of aquiculture on the ecological environment, enhancing the quality of composite feed is one important approach.
\end{abstract}

Keywords: Aquiculture, Ecological environment, Pollution

In recent years, with the gradual enhancement of living level, people's demands for aquatic products are more and more. Since 1999, China begun to implement the "zero increase" of fishing outputs, and implemented the "negative increase" of fishing outputs in recent years, so the supply of aquatic products becomes more and more depends on the aquiculture ( $\mathrm{Li}, 2002, \mathrm{P} .7-9)$. And the aquiculture is quickly developed because of people's more and more demands for the aquatic products. But some unreasonable phenomena such as the random discharge of aquiculture waste water, the abuse of medical medicines, and the escaping of aquatic animals have seriously influenced the ecological environment. In the article, the problems existing in Chinese aquiculture and the influences on the ecological environment are summarized, and corresponding advices are proposed.

\section{Problems existing in Chinese aquiculture}

\subsection{Employees'o verall cultural quality is low}

There are over ten millions personnel to directly or indirectly engage in the aquiculture, but they universally 
have lower cultural level, deficient relative professional knowledge, and lower management level, and they can not creatively study and apply their knowledge. The popularization degree and depth of the aquiculture is still deficient, and the pertinence and the technical content are lower.

\subsection{The research of fishery diseases is sufficient, and the abuse of medicines is universal}

New or stubborn fishery diseases can not be treated, and most diagnosis departments of aquatic diseases only have undeveloped instruments and weak technical power, and they can not distinguish bacteria, virus, vermin, nutritional disease, or syndrome, which directly influence correct medicine using. Once the disease comes on, the abuse of medicines is very universal. The medicines are mainly composed by human medicines and animal medicines, lack in pertinence and have bad treatment effect. And seriously residual medicines are polluting the environment and reducing the quality of water products.

\subsection{The environment protection consciousness in aquiculture is weak}

In aquiculture, some aquiculture enterprises or individuals only give attention to their immediate interests, and the traditional fishery which sacrificing natural resources and consuming large numerous materials still exists universally. Though various high-yield aquiculture methods such as industrial fish farming, cage fish culture, and running water fish culture are developed to some extent, but the ecological fishing and the environment protection consciousness are still deficient, and the random discharge of aquiculture waste waters without any disposal has deteriorated the whole aquiculture environment, and blocked the healthy and sustainable development of this industry.

\section{Harm of Chinese aquiculture to the ecological environment}

\subsection{Factors influencing the ecological environment in aquiculture}

\subsubsection{Residual feeds and excrements}

Feeds are the material base of aquiculture, and the source of main nutritional matters. Most feeds of aquiculture are outside source foods and given to aquatic animals directly ( $\mathrm{Li}, 1996, \mathrm{P} .8-84)$. Large numerous of residual feeds and the excrements of aquatic animals all impact the water environment. Braaten found that in the seawater cage culture of abalone, $20 \%$ of wet or dry feeds can not be eaten by aquatic animals, and directly disperse in the aquatic waters and become into the pollution source (Braaten B, 1983, P.6-7).

In the eaten feeds, there are only $25 \% \mathrm{~N}$ to be used for the growth of fishes, and other $65 \%$ of them are used for excrement, and $10 \%$ of them are excreted out of the fishes as excrements. That means that only $1 / 5$ feeds are utilized effectively, and others are discharged to the environment as the environmental pollution matters (Gowen R J, 1987, P.563-575 \& O'Sullivan A J, 1992, P.405-412). In the cage culture or the pond fish culture, the waste and the pollution of feeds of fresh or chilled small mixed fishes are more serious (Dong, 2000, P.572-582).

In Lin Yongtai's research (Lin, 1995, P.6-10) about the influence of Heilongtan Reservoir cage fish culture on the water environment, the content of total nitrogen (TN) in the feeds is $5.22 \%$, the content of total phosphor (TP) is $1.43 \%$, and there are $131.2 \mathrm{t} \mathrm{TN}$ and $35.9 \mathrm{t} \mathrm{TP}$. And the TN entering into the waters from feeds is $96.27 \mathrm{t}$ ( $73.38 \%$ of TN in feeds), and the TP entering into the waters from feeds is $34.04 \mathrm{t}$ (94.81\% of TP in feeds). It is obvious that the feeds which have not been eaten seriously impact the water environment. Funge-Smith et al (Funge-smith, 1998, P.117-133) studied the material balance in the shrimp pond of paddyfield, and found that only $10 \% \mathrm{~N}$ and $7 \% \mathrm{P}$ were utilized in the aquiculture, and others all entered into the environment by various forms.

\subsubsection{Pollution of aquatic medicines}

In modern aquiculture, especially in high-density aquiculture, to prevent diseases, eliminate harmful biology, disinfect and restrain polluted and damaged biology, multiple chemical medicines are used. The treatment medicines and disinfectors in aquiculture have been another big pollution source. Especially in the aquiculture of China, the abuse of medicines is very serious, which has impacted the environment seriously.

Solbe had reported that there were 23 kinds of chemical medicines used in the aquiculture of England, and the antibiotics used in the aquiculture of Norway in 1990 were more than the antibiotics in the agriculture (Gowen R J, 1992, P.23-48). In the aquiculture, quite part of used medicines would disperse into the environment, which would induce short-term or long-term regression of the environment. In the coastwise of Zhu-jiang Delta, bluestone was slathered to treat the shrimp disease, and the $\mathrm{Cu}$ pollution still exist in the water environment of this region quite seriously (Jia, 1997, P.78-82). 


\subsubsection{Escaping aquatic animals}

The escaping fishes in the aquiculture may diffuse diseases and change the inheritance composing of wild swarm, and seal lice might be one example (Jia, 1997, P.78-82). In many aquatic farms, when the epidemics happen in aquatic juvenile prawns, the prawns and waters will be discharged to the exterior environment, which may induce the diseases to be diffused to the nature, and bring harms for wide swarms.

At present, the output of haddocks around North Atlantic Ocean has exceeded $4 \times 10^{5}$ tons. The potential influence of the escaping aquatic fishes on the wide swarms has been emphasized by these countries. According to the report (ICES, 1997, P.102-106), there were 34\% 54\% escaping haddocks in the captured haddocks along the seashore of Norway from 1989 to 1996, and the escaping aquatic salmons occupied 10\% 21\% of the captured haddocks in Firth, and in Scotland, North Ireland, Canada and US, escaping aquatic salmons were also be inspected.

The experiments in Ireland, Norway and Spain showed that the energy of escaping aquatic fishes was less than the energy of wild ones. The escaping fishes would impact the amount change and spawning sites of wild swarms. To avoid these influences, experts advised to use sterile fishes such as triploid fishes and gynogenesis fishes or the swarms close to the local wild swarms. Iceland has constituted some rules to restrain these influences, such as the local swarms must be used to propagate the river salmons, and for the river which yearly fishing amount exceeded 500, the fishing cage must be put out of the bayou for $15 \mathrm{~km}$ (Gowen R J, 1992, P.23-48).

\subsubsection{The fishing intensity is further strengthened, which makes the inshore fishery resources further reduced}

To renew the deteriorated coastal fishery resources, the seawater aquiculture is encouraged in China $(\mathrm{Li}, 2002$, P.7-9). However, because most aquatic feeds are animal feeds, it will increase the fishing intensity on the contrary. First, the aquiculture needs large numerous of animal feeds, and except for part assorted feeds, some carnivorous fishes including Micropterus salmoides in fresh waters and the groupers in sea waters in China mainly eat captured natural mixed small fishes. The feed coefficient of fixed small fishes usually is $2 \sim 3$, some times it will achieve 5 8. Second, though some fishes eat assorted feeds, but the animal albumens in assorted feeds mainly come from fishmeal, and the large demand of fishmeal would certainly increase the fishing amount (Yang, 2000, P.30-33).

\subsection{Influences on the ecological environment}

\subsubsection{The influence on the physiochemical factor of aquatic waters}

The main influence of aquiculture on water quality is to increase the suspended substances and the nutritional salts in waters (Luo, 2002, P.28-30 \& Xu, 2003, P.204-206 \& 235 \& Zhang, 2003, P.54-59 \& Zhao, 2003, P.362-364), and the cage aquiculture could reduce the dissolving oxygen in the aquiculture region (Tang, 2003, P.46-48). Liu Shunke et al (Liu, 1991, P.46-48) measured the water quality of cage carp culture in Shuimotan Reservoir, and found that the water color changing form cyan to black brown, and the transparency descended quickly, and the lowest was $54 \mathrm{~cm}$. Chen Dechun's research result (Chen, 1993, P.23-26) showed that the total suspended substances, total $\mathrm{P}$, total $\mathrm{N}$, total $\mathrm{C}, \mathrm{BOD}, \mathrm{COD}$ were all higher than the control region, and the value of $\mathrm{pH}$ was a little lower than the non-aquiculture region, and the salinity and water temperature changed little, and the transparency and DO were obviously lower than the non-aquiculture region, which indicated that the wastes of cage aquiculture increased the total concentration of water nutriments and reduced the transparency of the waters. Therefore, red tides and water blooms occur frequently in Chinese water areas (Song, 1995, P.11-13).

The discharges of organic wastes and inorganic wastes produced by coastal fishery aquiculture would directly bring some phenomena such as the increase of organic loads and the eutrophication in some half-closed bays, for example, BOD increases, oxygen-poor and oxidation-reduction potential reduce, which will induce the reducing compounds (such as ammonia, sulfureted hydrogen and firedamp) increased, thiobacillus bloomed, the biomass, abundant degree and kind amount of large zoobenthos reduced (Wang, 2003, P.60-62). Other influences also include the acidification of pond soils, the decrease of biologic diversity, the increase of pathogene, and the occurrence of water bloom. The ammonia, sulfureted hydrogen and methane produced in settlings would also harm the aquatic animals (Shu, 2002, P.74-79). The pollution discharges of large aquatic farms (such as cage or pond) in the sea area that the water exchanges slowly would also induce red tides and threaten the safe production of fishes, shrimps and seashells (Folke C, 1989, P.234-243).

\subsubsection{The influence on bottom matters}

In the bottom mud of aquiculture, the contents of $\mathrm{C}, \mathrm{N}$ and $\mathrm{P}$ are higher than the contents in other settlings, and the oxygen consumption is also higher, and the residual feeds are often seen in settlings (Luo, 2002, P.28-30 \& 
Shu, 2002, P.74-79). When the organic matters cumulated in the mud bottom are too more, the physiochemical index of the bottom will be changed, and the decomposing function of microbiology is bloom, and the dissolving oxygen in the bottom mud is deficient and becomes into the reducing status because of oxygen-poor or zero-oxygen, and large numerous of sulfates in sea waters generate $\mathrm{H}_{2} \mathrm{~S}$ in the reducing environment, and it can diffuse to the depth of a few centimeters in the bottom because of the absorption function of the settlings. Comparing relative factors of the surface settlings in the aquiculture region and the non-aquiculture region, it is obvious that the contents of high-sulfide, COD, inorganic nitrogen and inorganic phosphor in the aquiculture region are all higher (Zhang, 2003, P.54-59). Ji Rubao et al's research (Ji, 1998, P.21-27) about the bay ecological system of shell aquiculture indicated that in the denseness region of shell, the settling function of biology is very obvious. Hatcher et al (Hatcker A, 1994, P.219-235) measured the mussel aquiculture region in the Upper South Cove of Canady, and found that the settling amount of the aquiculture region is always two times than the non-aquiculture region.

\subsubsection{The influence on planktons and bottom dwellers}

Generally, the input of outside-source materials and organics can increase the productivity of the planktons, and the high-density aquiculture would certainly influence the predominant swarms of planktons. Feeds make the nutrimental matters in waters to gradually increase, and the phytoplankton propagated largely at the beginning, but with the extension of time and the continual expansion of aquiculture scale, the nutrimental matters increase, the water quality deteriorates, the illumination reduces, so the amount of phytoplankton will begin to reduce (Chen, 2001, P.20-22).

Different alga kinds need different nutrimental elements, and in the continual deterioration of water quality, the dominant kind of alga always changes from diatom to blue alga. For example, seashell is a kind of filter feeder with strong filtering ability, and high-density aquiculture will impact the ecological system, and whether for the bottom seeding aquiculture (such as clam and oyster) or for the balsa aquiculture (such as mussel and scallop), seashells all can filter and incept phytoplankton and organic grains in waters, so they will obviously influence the swarm structure of phytoplankton, and increase the proportion of micro phytoplankton in the swarm (Ji, 1998, P.21-27).

The zoobenthos is good feeds for fishes, and the index to evaluate the water quality. The residual feeds in the aquiculture region and the dejections of fishes would change the nutrimental status of waters and the water quality, and correspondingly include the kind composing, amount and biology amount of zoobenthos. Lin Yongtai et al (Lin, 1995, P.6-10) surveyed the influence of cage fishing of Heilongtan Reservoir on the water environment, and found that the amount of zoobenthos in cage region was obviously less than the non-cage region, that was because that the nutriments were largely accumulated under the cages and around this region, and the DO in the settlings decreased, and the amount of zoobenthos significantly reduced, and the distance was far from the cage, and the influence was less. Behind the critical line, because of a little accumulation of organic matters, residual feeds and fishery dejections offered good nutrimental conditions for zoobenthos, which would increase the abundance of some kinds and reduce the others'. Kaspar et al (Kaspar H F, 1985, P.127-136) surveyed a mussel aquiculture region in New Zealand, and found that the multi-hair mussel occupied the dominant status in the aquatic region by comparing the swarm structures of zoobenthos, but its diversity was far lower than the non-aquiculture region.

\subsubsection{The influence on the diversity of biology}

The other influence of aquiculture on aquatic biology is that the escaping aquatic fishes would impact their neighboring biology. The escaping fishes in the aquiculture may diffuse diseases and change the inheritance composing of wild swarm (ICES, 1997, P.102-106), and infect local epidemics to wild swarms. The energy of escaping aquatic fishes was less than the energy of wild swarms. The escaping fishes would impact the amount change and spawning sites of wild swarms. Mills et al (Mills, 1983, P. 151-161) found that the influence of the fishes escaping from the cages or replanted intentionally on the wild fish swarm also would kill out local swarms by preying or feed competition. Especially once the cross-fertilized fishes and genetically engineered fishes generated by modern biological technology escape to the nature, the "gene pollution" may be induced, which will harm the inherit diversity of wild swarm in the nature (Chen, 2003, P.191-194).

\subsubsection{The influence on the ecological environment}

In the recent years, because of the development of aquiculture, the seductive profit of aquiculture has raised a aquatic tide in the world, most lakes, rivers, swamps, coastal lowlands and mudflats are changed into shrimp culture ponds and fish culture ponds (Paez-osuna F, 2001, P.229-231). These lowlands were mangroves, kaline soils and agricultural lands, and some of them were inhabiting, spawning and refuge places for many fishes and 
shellfishes. And these places could also be important drainage passes when floods, storms and cyclones come. In addition, in the water exchange from mainland to coastal waters, these places are very important buffers. Especially, the mudflat and mangrove regions exert more significant function to maintain coastal ecological environment (Liu, 1997, P.101-106). However, many shadow seas and mudflats were developed without systematic planning and technical research, and bland inning or destroying exploitation still exist for quick success and instant benefits, for example, the shrimp culture of large-scale development has seriously destroyed the ecological balance of many mudflats. Unreasonable development will destroy the ecological environment of shells, and the natural resource of mudflat shells (especially the important economic kind) were destroyed to different extents (China Ministry of Science and Technology, 1999).

\section{Advices to reduce the influence of aquiculture on the ecological environment}

The pollution of fishery ecological environment has impacted the quality of aquatic products of China, and reduced the international competitive force of Chinese aquatic products, and induced large economic losses, and blocked the sustainable development of Chinese fishery industry. To solve the problem of environmental pollution of aquiculture, following aspects are advised.

\subsection{Enhancing the quality of artificial formulated feeds}

Because most aquatic wastes come from feeds, to reduce these wastes, the nutrimental components and feeding mode should be changed. Adding digestible carbohydrate in feeds can enhance the utilization of proteins. And selecting the optimal proportion of the energy content and the protein content in feeds can reduce the excretion of nitrogen in feed, and the excreted energy in unit biology quantity will also be reduced. For the feeding, the proper feeding quantity should be confirmed, which can reduce the amount of feeds and scattered feeds and the loss of feeds, so it is very important to control the feed inception (Funge-smith, 1998, P.117-133). From 1975 to 1989 , the feed components of Northern European countries had been changed largely, and the fattiness in fishery feeds was enhanced for $27.5 \%$, the albumen was reduced for $31 \%$, and the energy was increased for $30 \%$. From 1987 to 1991, the yearly output of fishes in Finland increased three times, but the discharge of P from fishery aquiculture only increased for $23 \%$, and the causes include the enhancement of feed transformation rate, the decrease of P content, and the fishery output/ P discharge. From 1984 to 1991, the yearly output of aquatic fishes in Denmark increased four times, but the discharge of $\mathrm{N}$ only increased two times at the same term. The components of fishery feeds still can be improved further (ICES, 1992, P.32-35).

\subsection{Using fishery medicines correctly}

The prevention technology of aquatic fishery diseases is still lower. At present, most fishery medicines in aquiculture are human-animal sharing medicines, and the special fishery medicines are deficient, and the medicine using lacks in standards and pertinence in the aquiculture, and the confirmation of the dosage can not be based on scientific pharmacology, and the abuse of medicines still exist universally, even these medicines are entering into human bodies through the food chain. Therefore, the medicine dosage must the strictly controlled, and the performance and using method of fishery medicines must be known correctly, and the researches about the pharmacodynamics, the pharmacology, and the toxicology should be further strengthened, and the green fishery medicines with high efficiency and low poisons and without pollution and residuals should be studied to prevent the fishery diseases (Wang, 2004, P.21-26).

\subsection{Enhancing the management level of aquiculture}

In recent years, the main problem in the aquiculture is the management. At present, the reason that pollution of water environment and the destroying of coastal ecological environment by aquiculture in many places is the management of the aquiculture is not perfected and the development lacks in planning and control. Aiming at the problems existing in the aquiculture, the management should be urgently strengthened from macro and micro aspects. Following points should be emphasized, (1) constituting detailed aquatic development plan, (2) implementing rules about aquiculture resource development and management, and comprehensively utilizing the regulations of fishery resource management, (3) evaluating the aquatic capacity of various aquatic regions and the influence of aquiculture on ecological environment, (4) strictly managing the quality of aquatic seeds, feeds and medicines, (5) managing the safety of aquatic medicines and the aquatic products, (6) implementing aquatic science education and technical training for aquatic personnel, (7) enhancing aquatic personnel's environmental protection consciousness ( $\mathrm{Liu}, 2003$, P.24-25).

Only to develop the water resources and the aquatic biology resources by insisting the guidance of sustainable development, depending on science and technology, respecting the objective rules, protecting the ecological balance, and developing the fishery resources effectively and reasonably, the aquiculture of China in the 21 st century must be full of more vital forces and energies. 


\section{References}

Braaten B, Aure J, Ervik A, et al. (1983). Pollution on problem on Norwengian fish farms. Aquaculture Ireland, No. 14. P. 6-7.

Chen, Dechun. (1993). Impacts of Bait Casting Cage Fishing on Water Quality and Protection Measures. Reservoir Fisheries, No. 2. P. 23-26.

Chen, Lin, Yuan, Junfeng \& Bai, Guoqiang. (2003). Bilsafety Issue of Biotechnology. Journal of Shanghai Teachers University (Natural Sciences), No.32 (1). P. 191-194.

Chen, Yinghua, Yang, Yufeng \& Jiao, Nianzhi. (2001). Effects of Mariculture on the Planktnoic Community and Water Environments: A Review. Marine Sciences, No. 25 (10). P. 20-22.

China Ministry of Science and Technology. (1999). Development of Mudflat Resources in Shadow Sea. Beijing: Ocean Press.

Dong, Shuanglin, Pan, Kehou \& Uwe Brockmann. (2000). Review on Effects of Mariculture on Coastal Environment. Journal of Ocean University of Qingdao (Natural Science), No. 30 (4). P. 572-582.

Folke C. \& Kautsky N. (1989). The role of ecosystem for a sustainable development of aquaculture. Ambio, No.18. P.234-243.

Funge-smith, Briggs M R P. (1998). Nutrient budgets in intensive shrimp ponds: Implications for sustainability. Aquaculture, No.164 (18). P. 117-133.

Gowen R J. (1992). Aquaculture and environment. In De Pauw N, Joyze J eds. Aquaculture and environment. Ghent(Belgium): European Aquaculture Society Special Publication. No. 16. P. 23-48.

Gowen R J, Bradbury N B. (1987). The Ecological of salmonoid farming in coastal water: A review. Oceanogr Mar Biol Ann Rev, No.25. P. 563-575.

Hatcker A, Cent J \& Schiield B. (1994). Effects of suspended mussel culture on sedimentation, benthic tespitatton and ediment nutrient dynamics in a coastal bay. Marine Ecology Progress Series, No. 115. P. 219-235.

ICES. (1992). Environmental impacts of mariculture. In: ICES Cooperative Research report (NO.190). Copenhagen (Demark): ICES, P. 32-35.

ICES. (1997). Issues related to mariculture. In ICES Cooperative Research report (No. 222). Copenhagen (Denmark): ICES, P. 102-106.

Jia, Xiaoping, Cai, Wengui \& Lin, Qin. (1997). Main Pollution Problems in Chinese Coast Waters and Their Impacts on Seawater Aquiculture. Journal of Fishery Sciences of China, No. 4 (4). P. 78-82.

Ji, Rubao, Mao, Xinghua \& Zhu, Mingyuan. (1998). Influences of Shellfish Culture on the Ecological Environment of Bay. Journal of Oceanography of Huanghai \& Bohai Seas, No. 16 (1). P. 21-27.

Kaspar H F, Hopkinjon D C, Klump R V. (1985). Effect of mussel aquaculture on the nitrogen cycle and benthic communities in Kenepru Sounds New Zealand. Mar Biol, No. 85. P. 127-136.

Li, Aijie. (1996). Nutrition and Feed Science of Aquatic Animals. Beijing: China Agriculture Press. P. 8-84.

Li, Jieren. (2002). The Situation and Prospect of Chinese Aquatic Feeding Industry. Feed China, No.20. P.7-9.

Lin, Yongtai, Zhang Qing \& Yang Hanyun et al. (1995). Effects of Cage Culture on Water Environment. Reservoir Fisheries, No. 15 (6). P. 6-10.

Liu, Qing. (2003). Pushing the Legal Construction of Aquiculture and Promoting the Enhancement of Aquiculture Management Level. China Fisheries, No. 5. P. 24-25.

Liu, Shunke, Jiang, Weimin, Tian, Xiaofeng et al. (1991). Causes and Countermeasures of Water Quality Deterioration of Cage Carp Culture in the Reservoir of Shuimotan. Reservoir Fisheries, No. 23 (1). P. 46-48.

Liu, Yu \& Chen, Guizhu. (1997). Study on the Alga Swarm Structure and Bionomics of Futian Mangrove in Shenzhen. Acta Scientiarum Naturalium Universitatis Sunyatseni (Natural Sciences), No. 36 (1). P. 101-106.

Luo, Lin, Shu, Tingfei \& Wen, Yanmao. (2002). Effects of Aquaculture on Coastal Ecological Environment. Fisheries Science, No. 21 (3). P. 28-30.

Mills E L, Forney J L. (1983). Impact on Daphnia pulex of predation by young yellow perch in Oneida Lake, New York. Trans Am Fish Soc., No. 112. P. 151-161.

O'Sullivan A J. (1992). Aquaculture and user conflicts. In: De Pauw N and Joyce J eds, Aquaculture and the 
Environment, Ghent (Belgium):European Aquaculture Society Special Publication. No. 16. P. 405-412.

Paez-osuna F. (2001). The environment impact of shrimp aquaculture: A global perspective. Environmental pollution, No. 12(23). P. 229-231.

Shu, Tingfei, Luo, Lin \& Wen, Yanmao. (2002). Effects of Mariculture on Coastal Ecological Environment. Marine Environmental Science, No. 21 (2). P. 74-79.

Song, Chunyin \& Fan, Zhijie. (1995). Status of Chinese Coastal Red Tide and Research Development. The Administration and Technique of Environmental Monitoring, No. 7 (3). P. 11-13.

Tang, Yetao \& Jia, Houlei. (2003). Effects of Cage Culture on Water Environment. Reservoir Fisheries, No. 23 (1). P. 46-48.

Wang, Guangjun, Xie, Jun \& Wu, Jiamin. (2004). Healthy Culture of the Aquatic Animal and Research and Developing of Green Fishery Medicines. Fisheries Science \& Technology, No. 28 (12). P. 21-26.

Wang, Ruding. (2003). The Environmental Pollution by Marine Culture and Its Appropriate Prevention and Cure. Journal of Zhejiang Ocean University (Nature Science), No. 22 (1). P. 60-62.

Xu, Xirong, Wen, Yanmao \& Shu, Tingfei. (2003). Effect of Mariculture on Water Environment in Sea Area. Fisheries Science \& Technology Information, No. 30 (5). P. 204-206 \& 235.

Yang, Zhimin. (2000). The Influences of Fishmeal Supply of Peru and Chile on the Fishmeal Industry of China. Latin American Studies, No. 3. P. 30-33.

Zhang, Jian, Wu, Aoyu, Shi, Qingsong. (2003). Mariculture and Its Environment Effect in the Xiangshanggang Bay. Donghai Marine Science, No. 21 (4). P. 54-59.

Zhao, Anfang, Liu, Ruifang \& Wen, Yanmao. (2003). Effects on Water Environment in Different Aquacultures and Discussion on Cleaner Production. Environmental Pollution and Control, No. 25 (6). P. 362-364. 